\title{
Five-year follow-up of a food-based vitamin A intervention in Tanzania
}

\author{
Diana Kidala ${ }^{1}$, Ted Greiner ${ }^{2}$ and Mehari Gebre-Medhin ${ }^{2, *}$ \\ ${ }^{1}$ Tanzania Food and Nutrition Centre, Dar-es-Salaam, Tanzania: ${ }^{2}$ Department of Women's and Children's Health, \\ Section for International Maternal and Child Health, Uppsala University, S-751 85 Uppsala, Sweden
}

Submitted 4 October 1999: Accepted 7 January 2000

\begin{abstract}
Objective: To evaluate the long-term effects of a horticultural and nutrition education intervention in rural Tanzania.

Design: A quasi-experimental post-test design was used.

Setting: The research was carried out in 10 villages in Singida region, Tanzania.

Subjects: Mothers and their children aged 6-71 months $(n=236)$ from an experimental (Ilongero) and control (Ihanja) area were interviewed regarding knowledge and practices related to vitamin A nutrition. Intake of vitamin A-rich foods by the children during the 7 days prior to the interview was recorded. Stools were examined for helminths and serum samples were analysed for retinol and C-reactive protein (CRP) $(n=146)$ for the children aged 12-71 months.

Results: Knowledge and practices were more favourable to vitamin A intake in the experimental area than in the control area, and an increased frequency of intake of green leaves was associated with higher serum retinol values. The experimental area had lower mean serum retinol levels $\left(13.7 \mu \mathrm{g} \mathrm{dl}^{-1}, n=75\right)$ than the control area $\left(19.3 \mu \mathrm{g} \mathrm{dl}^{-1}, n=71\right)$. One likely confounder was the higher helminth infestation in the experimental area $(n=75,79 \%)$ than in the control area $(n=71,49 \%)(P<0.001)$. Children with helminths $(n=94)$ had a lower mean serum retinol level than those without $(n=52)\left(12.3 \pm 5\right.$ vs. $\left.24 \pm 10 \mu \mathrm{g} \mathrm{dl}^{-1} ; P=0.001\right)$.

Conclusions: Food-based vitamin A programmes can make sustainable improvements in knowledge and dietary practices but these may not necessarily be reflected in increases in serum retinol. Programme implementation and evaluation should take confounders into consideration as, in this case, helminth infestation.
\end{abstract}

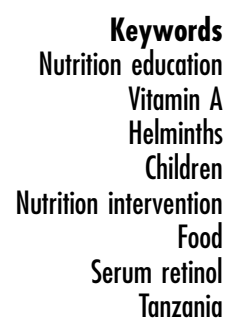

It is estimated that vitamin A deficiency (VAD) and xerophthalmia occur in about $6 \%$ of the Tanzanian population, $98 \%$ of those affected being children under 6 years of age ${ }^{1}$. This deficiency is a problem of public health significance mainly in the dry regions of central Tanzania ${ }^{2}$. As an immediate measure for controlling VAD, vitamin A supplements are to be provided to children with xerophthalmia, acute respiratory infections, protein energy malnutrition, prolonged diarrhoea and measles. To achieve a more sustained impact, emphasis is being placed on increased production and consumption of vitamin A-rich foods, control of childhood diseases through immunization and good environmental sanitation, and promotion of breast-feeding and appropriate weaning foods. Nutrition education is one of the strategies used for these purposes ${ }^{3}$.

It is now widely accepted that vitamin A is important in reducing mortality in children ${ }^{4,5}$, especially from deaths which are attributed to diarrhoea and measles 5 . Improvement of the vitamin A status of young children in areas where clinical signs of deficiency are evident has been reported to reduce their mortality rate by $23 \%{ }^{6}$. Night blindness and xerophthalmia have been associated with infrequent consumption of foods containing vitamin $\mathrm{A}^{7-9}$.

Some studies have found that intestinal helminths appear to have a negative impact on vitamin A status ${ }^{10,11}$ while others have not ${ }^{12,13}$. Higher levels of formal education among mothers are associated with higher nutritional status $^{14,15}$. Specific nutrition education to improve consumption of foods containing vitamin A has been reported to be effective ${ }^{16-18}$. However, few studies have looked into the extent to which the results of nutrition education are sustainable and can still be observed beyond the intervention period $^{19,20}$.

Increasing the supply of affordable food sources can also be effective. Home gardens, for example, can contribute to vitamin A intake and status ${ }^{21,22}$. Improvements in food processing and preparation techniques can also be effective. For example, solar-dried provitamin A fruits and vegetables for use during periods of scarcity tend to have a higher provitamin A content than sun-dried ones $^{23}$. 
Concern has been raised about the effectiveness of nutrition education in improving the diets of poor women if given in isolation of programmes that make improvements affordable ${ }^{24}$. Yet, in one study increases in household income were not significantly associated with the intake of dietary vitamin A to preschool children ${ }^{25}$. There is also little documentation of the impact of nutrition education interventions on knowledge, practices or nutritional status in an African setting ${ }^{26}$, particularly with respect to vitamin $\mathrm{A}$ intervention ${ }^{27}$. Further studies are needed to elucidate the whole chain of events from nutrition education through improved knowledge and practice to an enhanced vitamin A status, particularly their sustainability in natural settings. In addition, the role of possible confounders such as infections in these interventions needs to be further investigated.

A horticulture and nutrition education intervention had been carried out in the arid VAD-prone area of Singida, Tanzania in 1992/93. The present study was conducted 5 years later to look at programme sustainability and examine the possible impact of that programme on the knowledge and practices of the mothers in the area and on the vitamin A status of their preschool children. We also looked at the occurrence of intestinal helminths in the children, a possible confounder of nutritional status.

\section{Materials}

\section{The surveys}

A survey was carried out in November 1991 among preschool children aged 6-71 months in 10 villages in the semiarid Ilongero and Ihanja Divisions in the Singida Rural
District of Tanzania. Five villages in each division were randomly selected and data on serum retinol were collected among 226 children, 6-71 months of age. The results indicated that vitamin A deficiency was a serious public health problem: about $15 \%$ of the total sample had severe deficiency (serum retinol $<10 \mu \mathrm{g} \mathrm{dl}^{-1}$ ) and another $47 \%$ had low levels (serum retinol $<20 \mu \mathrm{g} \mathrm{dl}^{-1}$ ) 28 . Immediate measures were taken on behalf of all who took part in the study and showed signs of VAD or other diseases.

A pilot project based on long-term measures relevant for rural Tanzanian communities was then initiated in the five villages in the Ilongero Division with the aim of promoting increased production and consumption of vitamin A-rich foods and enhancing proper preparation of these foods (Table 1).

It was decided in 1998 to conduct a second survey in the same villages as in 1991, to evaluate whether sustainability had been achieved and to obtain information for potential replication to other affected areas. In this study Ilongero Division will be referred to as the experimental area and Ihanja Division as the control area.

The survey was conducted in November-December 1998 before the rains started, and thus controlled for possible seasonal effects. Apart from a summary report ${ }^{28}$, data from the baseline survey were not available and thus a quasi-experimental post-test design was used in the present study for comparing the control and experimental areas.

\section{Study population}

All households of the 10 villages, five in the Ilongero Division and five in the Ihanja Division, with children aged

Table 1 Activities performed in the llongero Division, 1992-1993

\begin{tabular}{|c|c|c|c|}
\hline Activity & People involved & Outcome & Year \\
\hline $\begin{array}{l}\text { Sensitization meeting for village } \\
\text { leaders and villagers conducted } \\
\text { by TFNC }\end{array}$ & Virtually all villagers & & 1992 \\
\hline $\begin{array}{l}\text { Two-day seminar on project } \\
\text { implementation and nutrition } \\
\text { education to PIC and village leaders } \\
\text { by TFNC }\end{array}$ & $\begin{array}{l}\text { Village leaders and } \\
\text { PIC in each village }\end{array}$ & & 1992 \\
\hline $\begin{array}{l}\text { Sensitization meeting by the PIC on: } \\
\text { - Problems associated with not eating } \\
\text { vitamin A-rich foods } \\
\text { - Proper preparation and storage of } \\
\text { vitamin A-rich vegetables } \\
\text { - Growing of vegetables and fruits } \\
\text { rich in vitamin A }\end{array}$ & Virtually all villagers & $\begin{array}{l}\text { - } 7000 \text { guava and pawpaw seedlings } \\
\text { distributed to } \mathrm{HH} \text { and primary schools } \\
\text { - } 1800 \mathrm{HH}(76 \% \text { of } \mathrm{HH}) \text { established } \\
\text { gardens } \\
\text { - All primary schools established/ } \\
\text { strengthened school gardens }\end{array}$ & 1992 \\
\hline $\begin{array}{l}\text { Two-day nutrition education seminar } \\
\text { conducted by TFNC on: } \\
\text { - Importance of backyard gardens } \\
\text { - Traditional vegetable preservation } \\
\text { - Weaning foods } \\
\text { - Vegetable cooking }\end{array}$ & $\begin{array}{l}20-30 \text { women in each } \\
\text { village selected from } \\
\text { area of the village }\end{array}$ & $\begin{array}{l}\text { - } 119 \text { women trained } \\
\text { Booklets distributed on: } \\
\text { Vitamin A deficiency and associated } \\
\text { problems ( } 100 \text { copies) } \\
\text { Weaning foods for Singida region } \\
\text { (100 copies) } \\
\text { Breast-feeding posters (20 copies) }\end{array}$ & 1993 \\
\hline
\end{tabular}

$\mathrm{HH}$, households; PIC, Project Implementation Committee; TFNC, Tanzania Food and Nutrition Centre. 
6-71 months, were listed, using the village register. Each village has approximately 200-300 households and the number of those with children aged 6-71 months ranged from 50 to 180. A table of random numbers was used to select 25 households in each village, giving a total of 250 households. The procedure for the selection of households and subjects is illustrated in Fig. 1. If the mother was not in the household on the day of the interview, then the nearest eligible household was chosen. If there was more than one preschool child in the household, an index child was randomly selected. Fourteen were not at home and no nearby replacements could be located. This resulted in 236 mother-child pairs (with an age range of 6-71 months) who were interviewed, as shown in Fig. 1. The final study population on which our retinol analyses are based was 146. In Table 2, these children are compared with those who are not included in the analysis for practical reasons. Most of those who were not included in the analysis were very young children; the final sample includes no children under 12 months and only seven children were 12-23 months old.

\section{Methods}

A structured questionnaire was used, including questions on the health status of the child, review of the child's $\mathrm{MCH}$

\section{Experimental area llongero Division \\ (5 villages)}

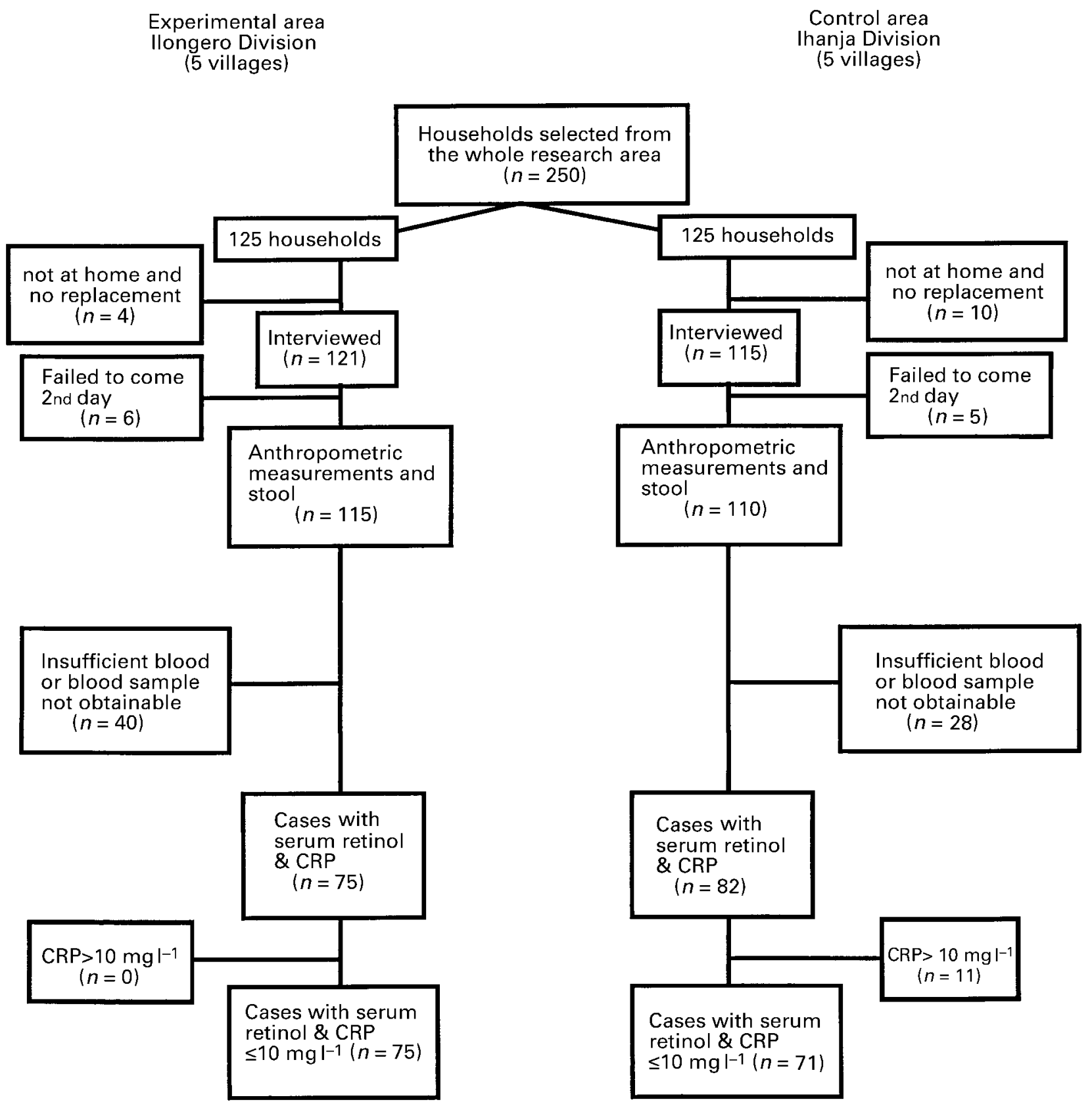

Fig. 1 The research subjects from the experimental and control areas 
Table 2 Some characteristics of the children in the final study population compared with those not included in the retinol analysis $(\mathrm{RA})$

\begin{tabular}{lccccc}
\hline & \multicolumn{2}{c}{ Experimental area } & & \multicolumn{2}{c}{ Control area } \\
\cline { 2 - 3 } & $\begin{array}{c}\text { Final study } \\
\text { population }\end{array}$ & $\begin{array}{c}\text { Not included } \\
\text { in RA }\end{array}$ & & $\begin{array}{c}\text { Final study } \\
\text { population }\end{array}$ & $\begin{array}{c}\text { Not included } \\
\text { in RA }\end{array}$ \\
\hline Number & 75 & 46 & & 71 & 44 \\
Mean age (years) & $47 \pm 14$ & $35 \pm 16$ & & $49 \pm 12$ & $43 \pm 16$ \\
Girls/Boys (\%) & $51 / 50 \%$ & $52 / 48 \%$ & & $48 / 52 \%$ & $57 / 43 \%$ \\
Mean consumption of DGLVs & $4.5 \pm 3.0$ & $5.3 \pm 2.9$ & & $3.2 \pm 2.8$ & $3.0 \pm 3.2$ \\
\% with helminths & $79 \%$ & $70 \%$ & & $49 \%$ & $59 \%$ \\
\hline DGLV, dark green leafy vegetable. & & & &
\end{tabular}

card, mother's knowledge and practices related to vitamin A nutrition, and the frequency of consumption during the past week of vitamin A-rich foods. Observations were also made of the presence of a home garden and the types of vitamin A-rich crops grown. The mother was asked about the number of days during the past week on which each of a list of vitamin A-rich foods was eaten by the index child.

The informed consent of the mother was obtained before participation in the research. Ethical clearance was obtained from the Ethics Committee, Faculty of Medicine, Uppsala University and from the Tanzania Food and Nutrition Research and Ethics Committee.

\section{Measurements of bealth indicators}

Anthropometric measurements were made on 225 of the 236 children. Weight was measured without shoes and with minimal clothing, using a battery-powered digital scale (Seca Inc., Columbia, MD) and recorded to the nearest $0.1 \mathrm{~kg}$. Height was measured with a measuring board marked in $0.1 \mathrm{~cm}$ divisions.

Stools ( $n=225$ ) were examined in the field using a wet preparation technique on a light microscope under low power on the same day to determine whether or not helminth eggs were present. About $5 \mathrm{ml}$ of venous blood was taken from the cubital vein, using disposable syringes and needles, for determination of serum retinol and CRP. CRP is an acute-phase reactant that was used to indicate possible infection or an inflammatory process among the children ${ }^{29}$. The blood samples were covered with a black cloth and left for $15 \mathrm{~min}$ at room temperature, and then transferred to a cool box. Within a few hours, the samples were centrifuged and serum was separated and frozen at $-30^{\circ} \mathrm{C}$ pending analysis. The samples were transported within 1 month to the laboratory in a frozen condition.

\section{Analytical procedures}

The frozen samples were analysed for serum retinol within 1 month of arriving at the laboratory, using high performance liquid chromatography (HPLC) ${ }^{30}$. The betweenseries coefficient of variation was $15 \%$. CRP was assayed by an enzyme-linked immunoadsorbent assay (ELISA) technique using in-house kits from DAKO (A/S Denmark) and a computerized Multiskan Eliza reader (Labsystems Finland). The detection level for CRP was $0.02 \mathrm{mgl}^{-1}$. The normal reference interval used for the study area was $\mathrm{CRP}<10 \mathrm{mgl}^{-1}$.

\section{Statistical analysis}

The Statistical Package for the Social Sciences (SPSS version 9.0) was used for data analysis. Differences between the experimental and control groups were calculated concerning variables related to knowledge, practice, serum retinol levels, and the number of days per week on which individual vitamin A-rich foods were eaten. Appropriate parametric or non-parametric statistical tests were chosen according to whether or not variables were normally distributed. The Mann-Whitney test, Pearson chi-square and Spearman's correlations were used.

\section{Results}

\section{Knowledge and practices}

Knowledge and practice, as measured by the indicators shown in Table 3, differed markedly between the two areas. Knowledge about possession of and use of solar driers was significantly higher in the experimental area.

Sixty-seven per cent of the experimental households were observed to have a home garden and $67 \%$ of these households were growing pawpaws and/or guavas (provided by the Tanzania Food and Nutrition Centre (TFNC)), compared to $32 \%$ and $20 \%$ in the control area, respectively ( $P=0.001$ in each case). Sixty-five per cent of the index children in the experimental area consumed vitamin A-rich foods more than 7 times a week, compared to $37 \%$ in the control area $(P=0.001)$. Addition of fat to the child's diet was similar in both areas but colostrum use was slightly higher in the experimental area.

\section{C-reactive protein}

The serum concentration of CRP ranged from 0.5 to $29.1 \mathrm{mg} \mathrm{l}^{-1}$ in the total study population $(n=161)$. All the 
Table 3 Knowledge and practices in the control and experimental areas

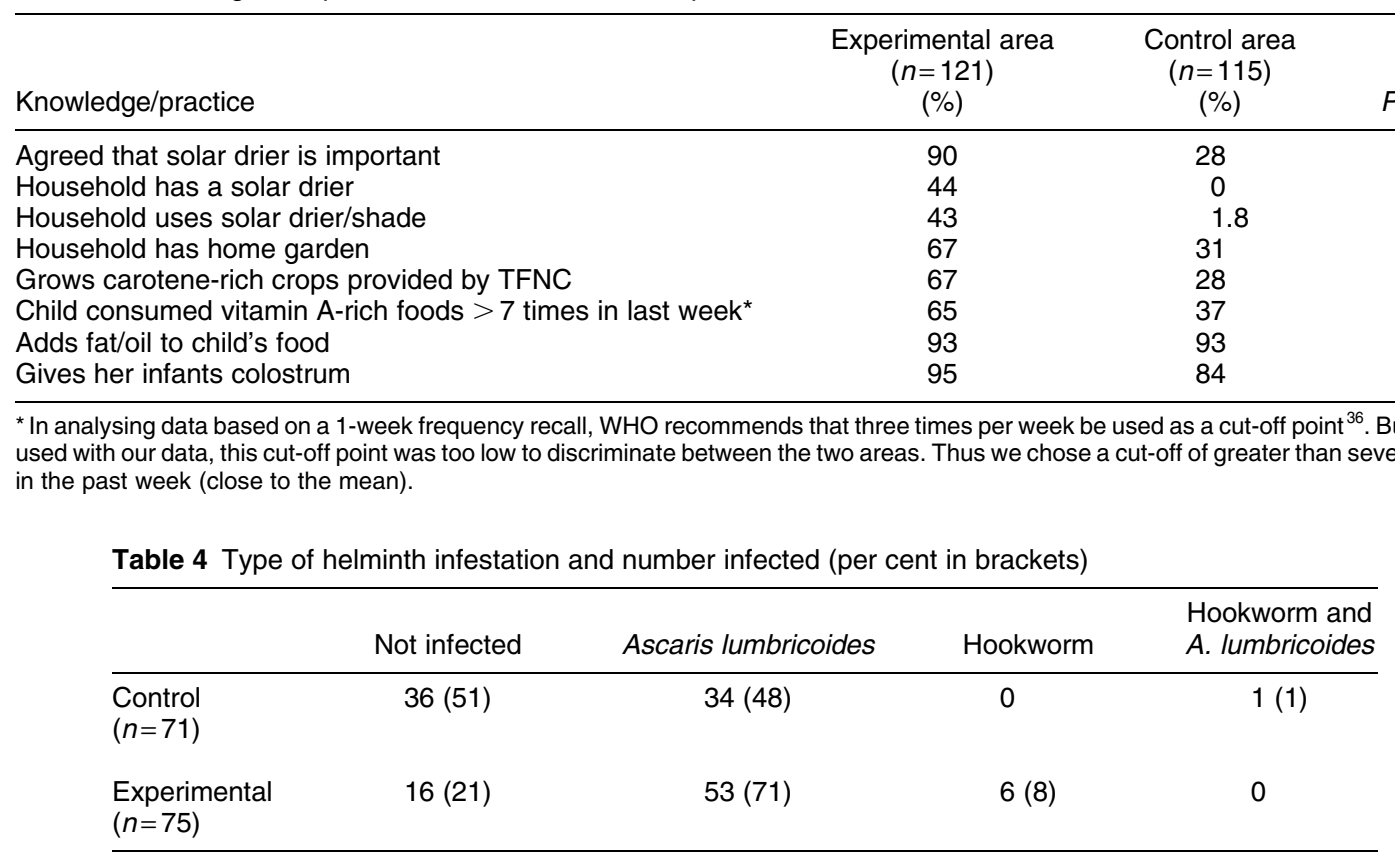

children in the experimental group $(n=75)$ and 71 of those in the control group had CRP $\leqslant 10 \mathrm{mgl}^{-1}$, i.e. within the normal reference interval. Four children did not have sufficient blood for retinol analysis and 11 children had CRP values $>10 \mathrm{mgl}^{-1}$. Children with CRP $>10 \mathrm{mgl}^{-1}$ were excluded from further data analysis as were six children for whom CRP values were not known.

\section{Serum retinol}

The serum retinol levels ranged from 2.2 to $55.1 \mu \mathrm{g} \mathrm{dl}^{-1}$ $(n=146)$ in the final study population; $22 \%$ had severe VAD (serum retinol $<10 \mu \mathrm{g} \mathrm{dl}^{-1}$ ) and $53 \%$ had low levels (retinol $<20 \mu \mathrm{g} \mathrm{dl}^{-1}$ ). The more often the children consumed green leafy vegetables, the higher their serum retinol (Spearman's rho $=0.21, P=0.01$ ). Five children among the 146 were still breast-feeding, one of whom was 12 months old, and the remaining four were between the ages of 22 and 38 months. There was no statistically significant difference between the mean serum retinol for those who were still breast-feeding $\left(15.2 \pm 12.5 \mu \mathrm{g} \mathrm{dl}^{-1}\right)$ and those who had stopped breast-feeding (16.2 \pm $9 \mu \mathrm{g} \mathrm{dl}^{-1}, P<0.65$ ). Only one of these five breast-fed children had helminths, with a serum retinol level of $11.2 \mu \mathrm{g} \mathrm{dl}^{-1}$, while the corresponding mean for the four without helminths was $16 \pm 14 \mu \mathrm{g} \mathrm{dl}^{-1}$. The children in the control area $(n=71)$, where no intervention was carried out, had a significantly higher mean serum retinol (19.4 \pm $\left.9 \mu \mathrm{g} \mathrm{dl}^{-1}\right)$ than those in the experimental area $(n=75)$ $\left(14 \pm 8 \mu \mathrm{g} \mathrm{dl}^{-1}\right)(P<0.0001)$.

\section{Impact of belminths on retinol}

Of the children for whom retinol values are known and whose CRP levels were $\leqslant 10 \mathrm{mgl}^{-1}$, $79 \%$ in the experimental villages $(n=75)$ and $49 \%$ in the control villages $(n=71)$ were infested with helminths (Pearson chi-square $=13.7, P=0.0002$ ) (Table 4$)$. The children with helminths in the two divisions combined $(n=94)$ had significantly lower mean serum retinol level (12.3 \pm $\left.5 \mu \mathrm{g} \mathrm{dl}^{-1}\right)$ than those without helminths $(n=52)(24 \pm$ $\left.10 \mu \mathrm{g} \mathrm{dl}^{-1}\right)(P=0.001)$ (Table 5). The difference in serum retinol between the experimental and control areas was no longer statistically significant when adjustment was made for helminth infection.

\section{Receipt of vitamin A capsules}

There was no significant difference between the two areas regarding the reported receipt of vitamin A capsules. Seven children in the experimental area and six in the control area had received such capsules. However, the capsules were received more than 6 months before the survey was carried out. The mean serum retinol level in the children receiving capsules in the experimental area was $10.0 \pm$ $9 \mu \mathrm{g} \mathrm{dl}^{-1}(n=7)$ and in the control area it was $20.9 \pm$ $4 \mu \mathrm{g} \mathrm{dl}^{-1}(n=6)$. A possible explanation for this difference is that a greater proportion in the experimental group had

Table 5 Mean serum retinol $\left(\mu \mathrm{gdl}^{-1}\right)$ in relation to helminth infection

\begin{tabular}{llc}
\hline Villages & Not infected & Infected \\
\hline $\begin{array}{l}\text { Experimental and control } \\
\text { combined }\end{array}$ & $24.0(n=52)^{\star}$ & $12.3(n=94)^{\star \star}$ \\
Control & $25.2(n=36)^{\star}$ & $13.3(n=35)^{\star \star}$ \\
Experimental & $21.2(n=16)^{*}$ & $11.7(n=59)^{\star \star}$ \\
\hline
\end{tabular}

Only when the asterisks are different are differences statistically significant $(P<0.05)$. 
helminths. The mean serum retinol level in children with helminths in the experimental group was $5.6 \pm 3 \mu \mathrm{g} \mathrm{dl}^{-1}$ $(n=4)$. The single child with helminths who had received vitamin A capsules quite a few years earlier in the control area had a serum retinol of $13.4 \mu \mathrm{g} \mathrm{dl}^{-1}$.

\section{Discussion}

The objective of the present study was to find out whether a horticulture and nutrition education programme previously carried out in a VAD-prone area of Tanzania had been successful in sustaining positive changes in knowledge and practices of the population towards an improvement of the vitamin A status of their children. An area in which no such intervention had been conducted served as a control area.

Similar to findings elsewhere ${ }^{17,18,31}$, the intervention programme appeared to have a positive impact on some indicators of nutrition knowledge and practice in the experimental area compared with the control area. Smitasiri et al. $^{31}$ and Hussain and Kvåle ${ }^{19}$ found evidence in Asia that such improvements can be sustainable. Here we provide similar results in an African context.

However, the experimental area had a significantly lower mean serum retinol than the control area. Others have reported no evidence of improvement in vitamin A status despite increases in consumption ${ }^{31}$. Greiner and Mitra ${ }^{17}$ reported from a study in Bangladesh that night blindness levels were not significantly decreased either by an increase in consumption of vitamin A-rich foods after a nutrition education intervention in the experimental area or by an increase in vitamin A capsule coverage in the control area. In rural India, Vijayaraghavan et al. ${ }^{18}$ found that, although there were improvements in knowledge, production and consumption of vitamin A-rich foods, the impact on the prevalence of Bitot's spot was not statistically significant and the mean serum retinol levels in the children participating in the trial did not differ significantly from those of non-participants.

In contrast, after a 3-year intervention programme of nutrition education and health promotion, Kuhnlein et al. ${ }^{32}$ reported improvements in serum retinol, carotene and folate levels in the overall community and in the iron status of teenagers, compared with the baseline values. Similarly, in Bangladesh, Hussain et al. ${ }^{8}$ found that 3 years of nutrition education was associated with reduced frequencies of night blindness. However, both studies lacked control areas and thus we cannot rule out secular change as an explanation for their findings.

In the present study, one likely reason for the unexpected findings was the higher proportion of children with helminth infestation in the experimental villages than in the control villages. Children with helminths had substantially lower levels of retinol than those without. When consideration was paid to helminth infestation in the analyses, there was no statistically significant difference in serum retinol levels between the study areas. In Brazil, Marinho et ll $^{33}$ found that supplementation with vitamin $\mathrm{A}$ and/or zinc was effective in raising the blood vitamin A levels only in parasite-free children. Similarly, in a study in Nepal it was found that children who had been given at least one course of mebendazole during the past 12 months had higher serum retinol levels than those who had not received this anthelminthic ${ }^{34}$. On the other hand, in areas with adequate access to vitamin A-rich foods and a good vitamin A status, the effect of helminths may be negligible, as shown in a study in Zanzibar ${ }^{35}$.

The post-test quasi-experimental evaluation method used here is subject to the risk that the experimental and control areas were not equivalent at baseline. While we were unable to obtain the baseline data, data in the existing report ${ }^{28}$ suggest that the overall retinol status was similar at baseline in the two areas. Although we do not know if other variables were also similar at baseline, it is highly plausible that many of the differences we found were due to the effects of the intervention. The clearest examples are related to awareness and use of solar driers, as shown in Table 3. It is evident from the studies mentioned above, that in the chain of events leading from nutrition education to improved knowledge and practice and hence a better vitamin A status, confounders can obscure the beneficial effects of interventions.

We conclude that nutrition education programmes initiated to improve dietary intake can lead to increases in knowledge and that people can change their practices for the better. These changes can be sustained over time and yet not be reflected in serum retinol values. Thus, consideration should be paid to factors that may stand in the way of improvement in nutritional status - in this case, helminth infestation. Further studies are needed to look in more detail at the interactions of various factors, both biological and otherwise, that may hinder improvement in the vitamin A status in natural settings and thus undermine the effectiveness and sustainability of interventions.

\section{Acknowledgements}

The authors wish to acknowledge the Tanzania Food and Nutrition Centre (TFNC) for conducting the laboratory analyses and helping with the fieldwork. We would also like to thank the TFNC and the Swedish International Development Cooperation Agency (Sida) for funding the research, and the Swedish Institute for providing a guest scholarship to Diana Kidala.

\section{References}

1 Kavishe FP. Nutrition-relevant Actions in Tanzania. Geneva: ACC/SCN, 1993.

2 TFNC. An overview of Singida Horticultural Potential in Relation to Promotion of Production and Consumption of Vitamin A Rich Fruits and Vegetables. Dar-es-Salaam: Tanzania Food and Nutrition Centre, 1991. 
3 TFNC. TFNC's 20th Anniversary 1973-1993. Dar-es-Salaam: Tanzania Food and Nutrition Centre, 1993.

4 Rahmathulla L, Underwood B, Thulasiraj R, et al. Reduced mortality among children in southern India receiving a small weekly dose of vitamin A. New Engl. J. Med. 1990; 323: 92935.

5 Ghana VAST Study Team. Vitamin A supplementation in northern Ghana. Effects on clinical attendance, hospital admissions, and child mortality. Lancet 1993; 342: 7-12.

6 Beaton GH, Martorell R, Aronson KJ, et al. Effectiveness of Vitamin A Supplementation in the Control of Young Child Morbidity and Mortality in Developing Countries. Geneva: ACC/SCN, 1993.

7 Mele L, West KPJ, Kusdiono Z, et al. and the Aceh Study Group. Nutritional and household risk factors for xerophthalmia in Aceh, Indonesia: a case-control study. Am. J. Clin. Nutr. 1991; 53: 1460-5.

8 Hussain A, Kvåle G, Ali K, Bhuyan AH. Determinants of night blindness in Bangladesh. Int. J. Epidemiol. 1993; 22: 1119-26.

9 Shanker AV, Gittelsohn J, West KPJ, Stallings R, Gnywali T, Faruque F. Eating from a shared plate affects consumption in vitamin A deficient Nepali children. J. Nutr. 1998; 1127-33.

10 Friis H, Mwaniki D, Omondi B, et al. Serum retinol concentrations and Schistosoma mansoni, intestinal helminths, and malarial parasitemia: a cross-sectional study in Kenyan preschool and primary school children. Am. J. Clin. Nutr. 1997; 66: 665-71.

11 Atukorala TMS, Lanerolle P. Soil-transmitted helminthic infection and its effect on nutritional status of adolescent school girls of low socioeconomic status in Sri Lanka.J. Trop. Pediatr. 1999; 45: 18-22.

12 Reddy V, Vijayaraghavan K, Mathur KK. Effect of deworming and vitamin A administration on serum vitamin A levels in preschool children. J. Trop. Pediatr. 1986; 32: 196-9.

13 Ahmed F, Mohiduzzaman M, Jackson AA. Vitamin A absorption in children with ascariasis. Br. J. Nutr. 1993; 69: $817-25$.

14 Mbago MCY, Namfua PP. Some determinants of nutritional status of one-to-four year-old children in low income urban areas in Tanzania. J. Trop. Pediatr. 1992; 38: 299-306.

15 Zeitlin MF, Megawangi R, Kramer EM, Armstrong HC. Mother's and children's intakes of vitamin A in rural Bangladesh. Am.J. Clin. Nutr. 1992; 56: 136-47.

16 Rahman MM, Islam MA, Mahalanabis D, Chowdhury S, Biswas E. Impact of health education on the feeding of green leafy vegetables at home to children of the urban poor mothers of Bangladesh. Public Health 1994; 108: 211-8

17 Greiner T, Mitra SN. Evaluation of the impact of a food-based approach to solving vitamin A deficiency in Bangladesh. Food Nutr. Bull. 1995; 16: 193-205.

18 Vijayaraghavan K, Nayak MU, Bamji MS, Ramana GNV, Reddy V. Home gardening for combatting vitamin A deficiency in rural India. Food Nutr. Bull. 1997; 18: 337-43.

19 Hussain A, Kvåle G. Sustainability of a nutrition education programme to prevent night-blindness in Bangladesh. Trop. Med. Int. Health 1996; 1(1): 43-51.

20 Smitasiri S, Sa-ngobwarchar K, Kongpunya P, et al. Sustaining behaviour change to enhance micronutrient status through community- and women-based interventions in north-east Thailand: vitamin A. Food Nutr. Bull. 1999; 20 243-51.

21 Bloem MW, Huq N, Gorstein J, et al. Production of fruits and vegetables at the homestead is an important source of vitamin A among women in rural Bangladesh. Eur. J. Clin. Nutr. 1996; 50: S62-7.

22 De Pee S, Bloem MW, Gorstein J, et al. Reappraisal of the role of vegetables in the vitamin A status of mothers in central Java, Indonesia. Am. J. Clin. Nutr. 1998; 68: 1068-74.

23 Solomons NW, Bulux J. Identification and production of local carotene-rich foods to combat vitamin A malnutrition. Eur. J. Clin. Nutr. 1997; 51: 39-45.

24 Brown LV, Zeitlin MF, Weld LH, et al. Evaluation of the impact of messages to improve the diets of lactating rural Bangladesh women on their dietary practices and the growth of their breast fed infants. Food Nutr. Bull. 1994; 15: 320-33.

25 Kennedy ET, Oniango R. Household and preschooler vitamin A consumption in southwestern Kenya. J. Nutr 1993; 123: 841-6.

26 Guptill KS, Esrey SA, Oni GA, Brown KH. Evaluation of a face-to-face weaning food intervention in Kwara state, Nigeria: knowledge, trial and adoption of a home-prepared weaning food. Soc. Sci. Med. 1993; 36: 665-72.

27 Parlato M, Gottert P. Promoting vitamin A in rural Niger: strategies for adverse conditions. In: Seidel RE, ed. Strategies for Promoting Vitamin A. Production, Consumption and Supplementation. Washington, DC: Academy for Educational Development, 1996; 8-25.

28 TFNC. Report on the Baseline Survey on Vitamin A Deficiency in Ilongero and Ihanja Divisions, Singida. Dar-es-Salaam: Tanzania Food and Nutrition Centre, 1992.

29 Hansson L. C-reactive protein in clinical practice: with special regard to infectious diseases. $\mathrm{PhD}$ thesis, Karolinska Institute, Sweden, 1996.

30 Speek AJ. Microdetermination of vitamin A in human plasma using high performance liquid chromatography with fluorescence detection. Chromatogr. Biomed. Applic. 1986; 382: 284-9.

31 Smitasiri S, Attig AG, Valyasevi A, Dhanamitta S, Tontisirin K. Social Marketing Vitamin A-Rich Foods in Thailand, 2nd edn. Bangkok: Institute of Nutrition, Mahidol University, 1993.

32 Kuhnlein HV, Burgess S. Improved retinol, carotene, ferritin, and folate status in Nuxalk teenagers and adults after a health promotion programme. Food Nutr. Bull. 1997; 18: 202-10.

33 Marinho HA, Shrimpton R, Giugliano R, Burini RC. Influence of enteral parasites on the blood vitamin A levels in preschool children orally supplemented with retinol and/ or zinc. Eur. J. Clin. Nutr. 1991; 45: 539-44.

34 Curtale F, Vaidya Y, Muhilal, Tilden RL. Ascariasis, hookworm infection and serum retinol amongst children in Nepal. Panminerva Med. 1994; 36: 19-21.

35 Stoltzfus R, Albonico M, Chwaya HM, Tielsch J, Savioli L. Virtual Elimination of Vitamin A Deficiency: Obstacles and Solutions for the Year 2000. Guatemala: International Life Sciences Institute, 1996.

36 WHO. Indicators for Assessing Vitamin A Deficiency and their Application in Monitoring and Evaluating Intervention Programmes. Geneva: WHO, 1996. 